\title{
FÓRUM
}

Submetido 20.10.2015. Aprovado 07.07.2016

Avaliado pelo processo de double blind review. Editores Científicos: Charbel José Chiappetta Jabbour, Rafael Teixeira e Susana Carla Farias Pereira

DOI: http://dx.doi.org/10.1590/So034-759020160506

\section{OS MELHORES E OS PIORES: O BOCA A BOCA EM SITES DE VAREJO ELETRÔNICO}

\author{
The best and the worst: Word-of-mouth in e-tail websites \\ Los mejores y los peores: El boca a boca en sitios web de comercio \\ electrónico al por menor
}

\begin{abstract}
RESUMO
Esta pesquisa busca analisar os fatores internos do boca a boca (BAB) no varejo eletrônico brasileiro, comparando os melhores e piores sites em quatro dimensões: intensidade, valência positiva, valência negativa e conteúdo, por meio do modelo de Goyette, Ricard, Bergeron, e Marticotte (2010). Sugere-se que a intensidade do BAB seja maior para os melhores sites, enquanto o grau de promoção (valência positiva) dos melhores sites seja menor que o grau de detração (valência negativa) dos piores sites. Esse resultado reforça achados na literatura, que apontam que BAB negativo é mais passional e extremo. Ainda, os resultados demonstram que fatores como confiança, velocidade de entrega e atendimento pós-compra reforçam tanto o $B A B$ positivo nos melhores sites quanto o $B A B$ negativo nos piores sites. Contudo, segurança das transações e facilidade de uso não reforçam o $B A B$ negativo nos piores sites, sugerindo um certo grau de comoditização desses fatores entre melhores e piores sites.
\end{abstract}

PALAVRAS-CHAVE | Comércio eletrônico, varejo eletrônico, boca a boca, modelagem de equações estruturais, comportamento do consumidor on-line.

\begin{abstract}
This paper aims to investigate the internal dimensions of Word-of-Mouth (WOM) behavior, comparing the best and the worst Brazilian e-tail websites in four dimensions: intensity, positive valence, negative valence and content. The research used for this paper is based on the multidimensional framework of Goyette, Ricard, Bergeron, and Marticotte (2010). It suggests that WOM intensity is higher in the case of the best websites, while the degree of promotion (positive valence) of the best websites is lower than the degree of detraction (negative valence) of the worst websites. This result supports previous findings, showing that negative WOM is passionate and extreme. Yet, elements such as trust, delivery time and post-purchase support, reinforce both positive WOM in the best websites and negative WOM in the worst websites. However, security of transaction and ease of use do not reinforce negative WOM in the worst websites, suggesting a certain degree of commoditization of such factors between the best and the worst websites.
\end{abstract}

KEYWORDS / E-commerce, e-tail, word-of-mouth, structural equation modeling, online consumer behavior.

\section{FABRÍCIO DE CARVALHO INOCÊNCIO}

fabcarvino@gmail.com

Doutorando em Administração de

Empresas pela Fundação Getulio

Vargas, Escola de Administração de

Empresas de São Paulo - São Paulo -

SP, Brasil

\section{ÉRICO VERAS MARQUES}

ericovmarques@gmail.com

Professor da Universidade

Federal do Ceará, Faculdade de

Economia Administração Atuária e

Contabilidade - Fortaleza - CE, Brasi

\section{RESUMEN}

Este estudio se propone analizar los factores internos del boca a boca (BAB) en el comercio electrónico al por menor brasileño, comparando los mejores y los peores sitios web en cuatro dimensiones: intensidad, valencia positiva, valencia negativa y contenido, por medio del modelo de Goyette, Ricard, Bergeron, y Marticotte (2010). Se sugiere que la intensidad del BAB sea mayor para los mejores sitios web, mientras el grado de promoción (valencia positiva) de los mejores sitios web sea menor que el grado de detracción (valencia negativa) de los peores sitios web. Ese resultado refuerza hallazgos en la literatura que señalan que el BAB negativo es más pasional y extremo. No obstante, los resultados demuestran que factores como confianza, velocidad de entrega y servicio postcompra refuerzan tanto el $B A B$ positivo en los mejores sitios web como el BAB negativo en los peores sitios web. Sin embargo, la seguridad de las transacciones y la facilidad de uso no refuerzan el BAB negativo en los peores sitios web, lo que sugiere un cierto grado de comoditización de esos factores entre los mejores y los peores sitios web.

PALABRAS CLAVE I Comercio electrónico, comercio electrónico al por menor, boca a boca, modelado de ecuaciones estructurales, comportamiento del consumidor online. 


\section{INTRODUÇÃO}

Devido à credibilidade e influência que são atribuídas a uma recomendação entre conhecidos (Kozinets, Valck, Wojnicki, \& Wilner, 2010), o boca a boca (BAB) acaba por destacar-se em relação a outras fontes de informação sobre produtos e marcas, e posiciona-se como um fenômeno crítico para o varejo eletrônico, dado que a recomendação não se restringe a produtos, englobando também os canais de varejo eletrônico (Baptista \& Botelho, 2007).

Existe uma tendência na literatura em estudar fatores que antecedem ou sucedem o BAB (Andrade \& Brandão, 2012; Chevalier \& Mayzlin, 2006; Gauri, Bhatnagar, \& Rao, 2008; Henning-Thurau, Gwinner, Walsh, \& Gremler, 2004; Kumar \& Benbasat, 2006; Park \& Lee, 2009; Tubenchlak, Faveri, Zanini, \& Goldszmidt, 2015; Vieira, Matos, \& Slongo, 2009).

As relações entre seus fatores internos, contudo, ainda representam uma lacuna a ser investigada. Para tal, é necessário medir o construto de maneira integrada, considerando todas as suas dimensões internas, algo só possível com modelos multidimensionais (Goyette et al., 2010).

Segundo Goyette et al. (2010), o BAB sobre comércio eletrônico em geral possui quatro dimensões: intensidade (o quanto é frequente e disperso), valência positiva (o quanto é favorável), valência negativa (o quanto é desfavorável) e conteúdo (o que é comunicado).

A pesquisa de Goyette et al. (2010) estudou sites populares (preferidos pelos usuários) do Canadá e apresentou forte valência positiva no construto $B A B$, sem ocorrência de valência negativa. Esse comportamento é diferente do contexto brasileiro, em função da presença valência negativa no BAB (Andrade \& Brandão, 2012; Sandes \& Urdan, 2010).

A fim de captar as nuances do fenômeno BAB a partir de experiências pós-compra tanto positivas quanto negativas, um modelo multidimensional adaptado de Goyette et al. (2010) é aplicado em um grupo de melhores sites (preferidos) e outro de piores sites (preteridos), apontados por consumidores brasileiros.

Dessa forma, o objetivo desta pesquisa é analisar os fatores internos do BAB sobre sites de varejo eletrônico no Brasil, comparando os melhores e piores sites indicados por consumidores. A pesquisa tem as seguintes questões de partida: (1) Como se estabelecem as dimensões intensidade e valência positiva e negativa do BAB no varejo eletrônico brasileiro, em relação aos melhores e piores sites? (2) Como os fatores da dimensão conteúdo se relacionam com as demais valências do $B A B$, em relação aos melhores e piores sites?

0 artigo está dividido da seguinte forma: após a introdução, tem-se, no referencial teórico, a revisão da literatura acerca das dimensões dos construtos do BAB e são apresentadas as hipóteses de pesquisa; na metodologia, são apresentados o modelo de pesquisa e os procedimentos de coleta de dados; na análise dos resultados, são apresentados os resultados da pesquisa e a verificação das hipóteses de pesquisa; na conclusão, é apresentado o resumo dos achados, juntamente com sugestões para estudos futuros e limitações; e, nas referências, são apresentadas as fontes consultadas.

\section{REFERENCIAL TEÓRICO}

A seguir, são apresentados o referencial teórico e hipóteses de pesquisa.

\section{A multidimensionalidade do BAB}

O BAB consiste na transmissão de comunicação informal sobre produtos direcionada a outros consumidores (Westbrook, 1987), na qual expressa alta credibilidade em relação às decisões de compra (Kozinets et al., 2010).

Segundo Allsop, Bryce, e Hoskins (2007), a mensagem de $B A B$ tem um número de dimensões que afeta a forma como a comunicação é propagada. Da perspectiva de quem promove a comunicação, Harrison-Walker (2001) agrupou alguns construtos do $B A B$ em duas dimensões fundamentais: favorabilidade ou valência e atividade. Posteriormente, Goyette et al. (2010) realizaram um estudo no qual foram identificadas quatro dimensões, especificamente em comércio eletrônico de maneira geral: intensidade (o quanto é frequente e disperso), valência positiva (o quanto é favorável), valência negativa (o quanto é desfavorável) e conteúdo (sobre quais assuntos específicos os consumidores conversam).

No estudo de Goyette et al. (2010), valência positiva foi a dimensão que explicou a maior parte da variância no construto $B A B$, sendo seguida por intensidade, conteúdo e valência negativa. Dado tal resultado, os pesquisadores lançaram a seguinte questão: A propagação de valência positiva é forte especificamente no contexto de comércio eletrônico?

Há algumas respostas que podem justificar o alto poder explicativo da valência positiva no trabalho de Goyette et al. (2010). A literatura relacionada ao BAB apresenta evidências de que qualidade do serviço (Parasuraman, Zeithaml, \& Berry, 1988) e satisfação (Matos, 2011) são fatores que antecedem o BAB. Como na pesquisa de Goyette et al. (2010) foram selecionados os sites mais populares do Canadá, seria natural que a lista de sites investigados possuísse alto índice de BAB positivo, sendo os mais populares e utilizados.

Os achados de Sandes e Urdan (2010) e Andrade e Brandão (2012) sobre o varejo eletrônico brasileiro apresentaram evidências 
de valência negativa. Isso possibilita uma oportunidade de investigação mais aprofundada acerca da relação entre $B A B$ e preferência de sites, na qual se supõe encontrar BAB negativo em sites não preferidos (preteridos), testando a generalização acerca da valência positiva de Goyette et al. (2010) no comércio eletrônico.
Considerando uma análise simultânea sobre os melhores sites (preferidos) e piores sites (preteridos) apontados por consumidores brasileiros, a partir do modelo desenvolvido por Goyette et al. (2010), espera-se encontrar as seguintes relações entre as dimensões do BAB, conforme Figura 1.

\section{Figura 1. Hipóteses referentes às dimensões do BAB nos melhores e piores sites}

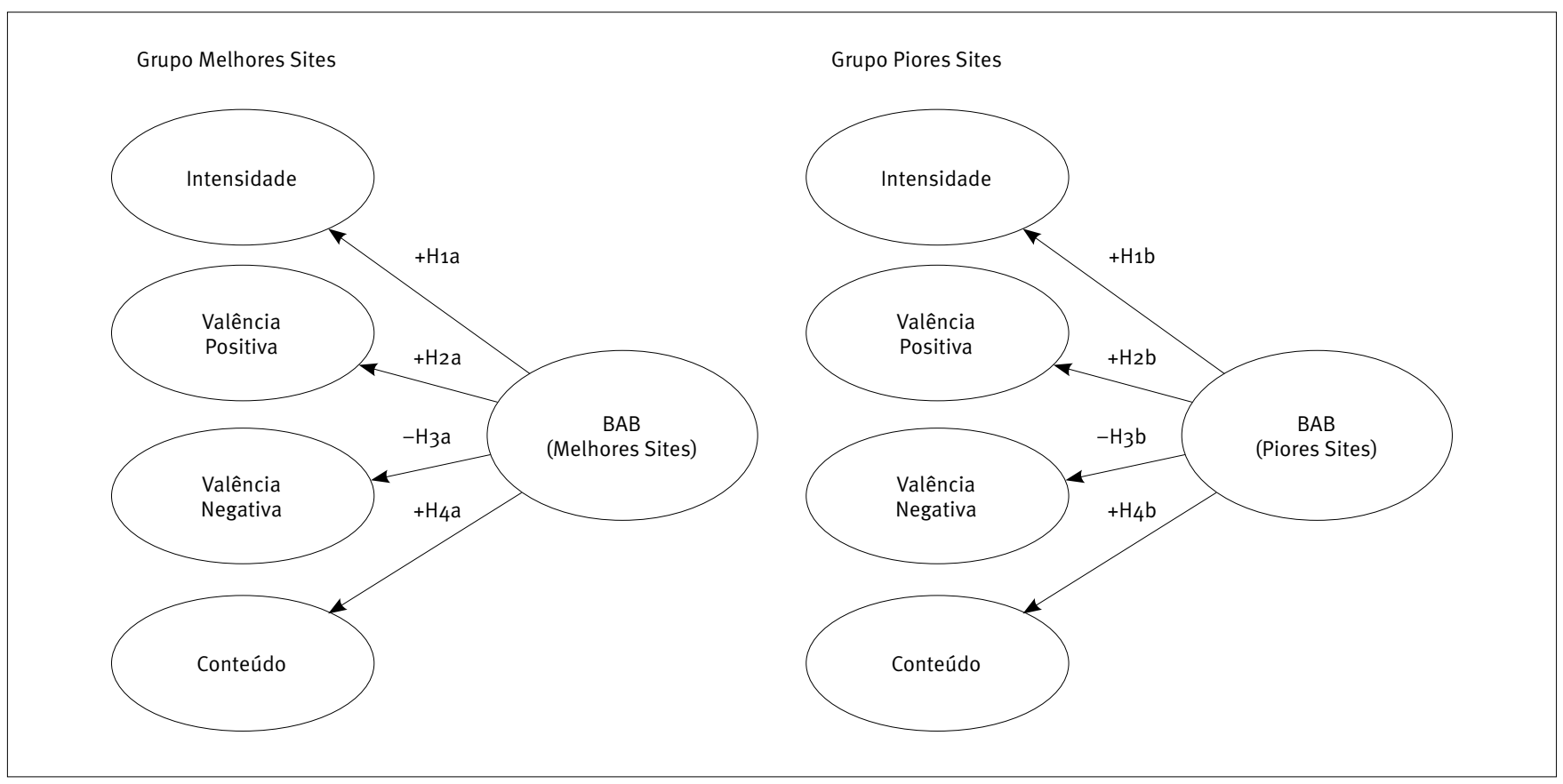

Fonte: Adaptado de Goyette et al. (2010).

Observa-se que é esperado que a valência negativa não tenha uma relação com $B A B$ dos melhores sites e que valência positiva não tenha uma relação com $B A B$ dos piores sites. Dessa forma, são apresentadas as seguintes hipóteses em relação à dimensionalidade do BAB:

H1a: Intensidade tem relação significativa com BAB nos melhores sites

$\mathrm{H}_{1} \mathrm{~b}$ : Intensidade tem relação significativa com $\mathrm{BAB}$ nos piores sites

H2a: Valência positiva tem relação significativa com BAB nos melhores sites

H2b: Não há relação significativa entre valência positiva e $B A B$ nos piores sites

H3a: Não há relação significativa entre valência negativa e $\mathrm{BAB}$ nos melhores sites
$\mathrm{H}_{3}$ b: Valência negativa tem relação significativa com $B A B$ nos piores sites

H4a: Conteúdo tem relação significativa com BAB nos melhores sites

H4b: Conteúdo tem relação significativa com $B A B$ nos piores sites

A seguir, é apresentada a discussão relacionada às dimensões intensidade, valência positiva e valência negativa do BAB.

\section{Intensidade, valência positiva e valência negativa do $B A B$}

Harrison-Walker (2001) define que intensidade (ou atividade) do $\mathrm{BAB}$ representa o engajamento de um indivíduo na comunicação, por meio da (1) frequência em que é comunicado algo, (2) quantidade de pessoas em que a comunicação é repassada e (3) quantidade relativa de informação passada. 
A relevância da intensidade no BAB está relacionada à força da comunicação, dado que o volume de informação impacta a popularidade do argumento (Khare, Labrecque, \& Asare, 2011), e, em alguns casos, essa força relaciona-se positivamente com vendas futuras (Dhar \& Chang, 2009).

Já valência ou louvor (praise) refere-se à natureza da comunicação acerca de um produto ou serviço, podendo ser favorável/positiva/promotora, neutra e desfavorável/negativa/ detratora (Goyette et al., 2010). Allsop et al. (2007) também definem valência como polaridade, possuindo as mesmas propriedades. A literatura relacionada ao BAB apresenta evidências de que satisfação, confiança e qualidade percebida são fatores que antecedem uma valência positiva (Matos, 2011; Parasuraman et al., 1988; Srinivasan, Anderson, \& Ponnavolu, 2002), e, dessa forma, um BAB positivo pode resultar em vendas futuras (Chevalier \& Mayzlin, 2006).

Todavia, a literatura parece dedicar-se mais à valência negativa. Segundo Cheung e Thadani (2010), a maior frequência de estudos encontra-se em entender o BAB negativo, principalmente 0 extremo. Nesse sentido, Richins (1983) encontrou evidências de que o BAB negativo depende do grau de insatisfação com o produto ou serviço experimentado pelo consumidor. Quando uma insatisfação mínima é experimentada, é mais provável que os consumidores nem reclamem ou gerem $B A B$ negativo. Quando a insatisfação é grave, consumidores tendem a reclamar, independentemente de outros fatores envolvidos no contexto de consumo do produto ou serviço.

Dessa forma, as pessoas tendem a engajar-se mais em mensagens negativas do que em mensagens positivas, muito em função de alertar conhecidos sobre más decisões acerca da aquisição de produtos ou serviços (Allsop et al., 2007; HarrisonWalker, 2001; Stokes \& Lomax, 2002).

Esse fenômeno corrobora Sweeney, Soutar, e Mazzarol (2005), que demonstraram que o $\mathrm{BAB}$ negativo pode estar mais associado a uma atitude passional do consumidor, com o objetivo de retaliação, enquanto o $\mathrm{BAB}$ positivo já assume uma resposta mais racional do consumidor. Também há uma convergência com os achados de Matos (2011), que encontrou evidências de que valência negativa possui uma associação forte com quebra de lealdade, justificando um comportamento forte e passional, algo que poderia ser relatado nos piores sites (preteridos) da presente pesquisa.

Considerando que a literatura apresenta achados da força do BAB negativo em relação ao BAB positivo (Allsop et al., 2007; Harrison-Walker, 2001; Richins, 1983; Stokes \& Lomax, 2002; Sweeney et al., 2005), são apresentadas as seguintes hipóteses de pesquisa:

$\mathrm{H}_{5}$ : Intensidade dos piores sites é maior que intensidade dos melhores sites
H6: Valência negativa dos piores sites é maior que valência positiva dos melhores sites

A seguir, é apresentada a discussão sobre a dimensão conteúdo do BAB e sua relação com valência.

\section{Relação entre valência e conteúdo no BAB}

Goyette et al. (2010) afirmam que é relevante identificar "sobre o que” os consumidores estão conversando, dessa forma, há necessidade de adicionar a dimensão conteúdo no modelo de mensuração do $B A B$, a fim de captar fatores que possam gerar valor de conversa para uma comunicação BAB.

De fato, o conteúdo das mensagens no BAB possui implicações relevantes. O teor do conteúdo das postagens influencia outros consumidores em uma comunicação $B A B$, dado que o conteúdo criado pelo consumidor é orientado ao usuário, e muitas vezes descreve o produto e medidas de desempenho do ponto de vista de um usuário, em situações reais de uso (Bickart \& Schindler, 2001). Dessa forma, há uma relação entre comunicação $\mathrm{BAB}$ e fatores ou atributos de produtos e serviços específicos de um determinado segmento (Subramani \& Rajagopalan, 2003).

No trabalho de Goyette et al. (2010), foram considerados os seguintes fatores para compor a dimensão conteúdo: velocidade de entrega, preços, qualidade do produto, segurança das transações, usabilidade (facilidade de uso) e variedade de produtos.

No entanto, é necessário identificar outros fatores dentro do contexto do varejo eletrônico brasileiro que sejam relevantes para os consumidores, a fim de construir um modelo de mensuração capaz de captar o fenômeno de maneira integrada e adequado ao âmbito local.

Algumas pesquisas fornecem evidências de características específicas que acarretam a decisão de escolha de canais e consequentes implicações na comunicação $B A B$, que não foram contemplados no modelo original de Goyette et al. (2010), tais como confiança (Baptista \& Botelho, 2007; SchrammKlein, Swoboda, \& Morscheet, 2007; Turban \& King, 2004) e atendimento pós-compra (Baptista \& Botelho, 2007; Barreto, Hor-Meyll, \& Chauvel, 2011; Forbes, Kelley, \& Hoffman, 2005; Lima, 2010; Turban \& King, 2004).

Dessa forma, é relevante analisar achados na literatura relacionados a fatores específicos do canal de vendas, como confiança e atendimento pós-compra (ambos a serem integrados ao modelo), e velocidade de entrega, facilidade de uso e segurança nas transações (já presentes no modelo utilizado). Também é oportuno realizar uma investigação sobre a relação desses itens com as valências do BAB, algo não contemplado no trabalho de Goyette et al. (2010). 
Não serão feitas considerações ou hipóteses sobre os fatores presentes no modelo de Goyette et al. (2010) que tratam de produto (como preço, variedade e qualidade). Contudo, esses fatores serão mantidos no modelo desta pesquisa, a fim de contemplar todos os itens do modelo original de Goyette et al. (2010). A seguir, é apresentada a revisão relacionada aos fatores do conteúdo comtemplados no escopo desta pesquisa.

\section{Confiança}

No contexto do varejo eletrônico, confiança é definida como a disposição de consumidores em acreditar em atributos relacionados a terceiros (McKnight \& Chervany, 2002), a qual tem como objetivo funcional reduzir a complexidade em situações de incerteza numa decisão de compra (Chang, Cheung, \& Lai, 2005). Dessa forma, quanto maiores forem as consequências negativas que enfrenta um comprador em perceber alto risco, maior será a necessidade de confiança (Grazioli \& Jarvenpaa, 2000).

Moshrefjavadi, Dolatabadi, Noubarkhsh, Poursaeedi, e Asadollahi (2012) reforçam que, no varejo eletrônico, os clientes não possuem qualquer sentido aprofundado sobre o produto que veem na internet (visão, tato, paladar, olfato e audição). Assim, eles podem desenvolver baixa confiança, devido à falta de comunicação face a face. Dessa forma, quanto maior a confiança, maior a predisposição do consumidor para comprar no comércio eletrônico (Schramm-Klein et al., 2007; Turban \& King, 2004). Esse fator também foi evidenciado no varejo eletrônico brasileiro em relação à escolha de canais (Baptista \& Botelho, 2007).

Assim, são formuladas as seguintes hipóteses acerca da confiança:

H7a: Valência positiva dos melhores sites tem relação significativa com confiança

H7b: Valência negativa dos piores sites tem relação significativa com confiança

\section{Atendimento pós-compra e velocidade de entrega}

Outros pesquisadores dedicam seus esforços a compreender o impacto da qualidade do canal na satisfação do consumidor, a fim de reduzir falhas comuns que acontecem no setor. Forbes et al. (2005) mapearam as principais falhas e motivos de reclamações no varejo eletrônico. Os principais motivos de reclamações estão relacionados ao serviço de entrega do produto, principalmente prazos, e falhas no atendimento, principalmente em situações pós-compra.
Barreto et al. (2011) analisaram 720 depoimentos de consumidores brasileiros em sites dedicados a reclamações, com a finalidade de mapear as principais razões de insatisfação com compras realizadas na internet. Os pesquisadores também encontraram evidências de que velocidade no serviço de entrega do produto e falhas no atendimento pós-compra parecem não atender bem às expectativas dos consumidores. Esses fatores também foram demonstrados por Turban e King (2004), Lima (2010) e em pesquisa realizada pelo eBit sobre o varejo eletrônico brasileiro (Webshoppers, 2013).

Dessa forma, entendendo que velocidade de entrega e atendimento pós-compra são fatores relevantes para o consumidor, infere-se que estes estejam presentes na comunicação BAB da seguinte forma:

H8a: Valência positiva dos melhores sites tem relação significativa com atendimento pós-compra

H8b: Valência negativa dos piores sites tem relação significativa com atendimento pós-compra

H9a: Valência positiva dos melhores sites tem relação significativa com velocidade de entrega

Hgb: Valência negativa dos piores sites tem relação significativa com velocidade de entrega

\section{Facilidade de uso e segurança nas transações}

Os dois últimos fatores possuem um ponto controverso na literatura. Apesar de alguns autores referenciarem usabilidade ou facilidade de uso como um atributo relevante para os consumidores (Turban \& King, 2004; Vieira et al., 2009), trabalhos mais recentes, como o de Costa e Marques (2011), encontraram evidências de que, nos sites de varejo eletrônico no Brasil, existe um alto índice de utilização de princípios referentes à usabilidade, demostrando que o setor pode estar nivelado em relação a esse atributo. Da mesma forma, apesar de segurança nas transações também ser um item relevante para os consumidores (Vieria et al., 2009), o recurso não é mais exclusivo dos líderes de mercado (Webshoppers, 2013).

Lima (2010) ressalta que facilidade de uso e segurança nas transações não representam mais vantagens competitivas para um site de varejo eletrônico, já que o consumidor naturalmente infere que todo site as deva possuir. Isso evidenciaria uma certa comoditização em relação a esses aspectos.

Assim, em relação a esses dois atributos no $B A B$, o comportamento esperado apresenta-se da seguinte forma: 
H10a: Não há relação significativa entre valência positiva dos melhores sites e facilidade de uso

H1ob: Não há relação significativa entre valência negativa dos piores sites e facilidade de uso

H11a: Não há relação significativa entre valência positiva dos melhores sites e segurança nas transações

H11b: Não há relação significativa entre valência negativa dos piores sites e segurança nas transações

São apresentadas, no total, 20 hipóteses para verificação nesta pesquisa. A seguir, é apresentada a metodologia.

\section{METODOLOGIA}

Dada a natureza multivariada dos construtos estudados, é utilizada a técnica de modelagem de equações estruturais chamada Análise Fatorial Confirmatória (AFC) de $2^{\text {a }}$ Ordem. Isso em razão de uma justificativa teórica para a existência de fatores hierárquicos superiores (Marôco, 2010), no caso, o BAB. A seguir, são apresentados o modelo de pesquisa e os demais procedimentos metodológicos.

\section{Modelo de pesquisa}

As variáveis são operacionalizadas baseando-se no modelo elaborado por Goyette et al. (2010), que consiste em medir o BAB em quatro dimensões: intensidade, valência positiva, valência negativa e conteúdo.

Em razão de melhor adequação ao contexto do varejo eletrônico brasileiro, na dimensão conteúdo são acrescentados itens referentes a atendimento pós-compra e confiança, em função da frequência destacada na literatura. Outra mudança é referente a dois itens que medem aspectos semelhantes: 0 item "eu discuto sobre a facilidade de transações" foi removido, dado que o item "eu discuto sobre a facilidade de uso do site" incorpora aspectos relacionados à usabilidade das transações. Os demais itens se mantêm constantes em relação ao modelo original de Goyette et al. (2010).

Dessa forma, 15 itens são utilizados para medir quatro dimensões do construto BAB, conforme a Figura 2:

\section{Figura 2. Diagrama de caminhos}

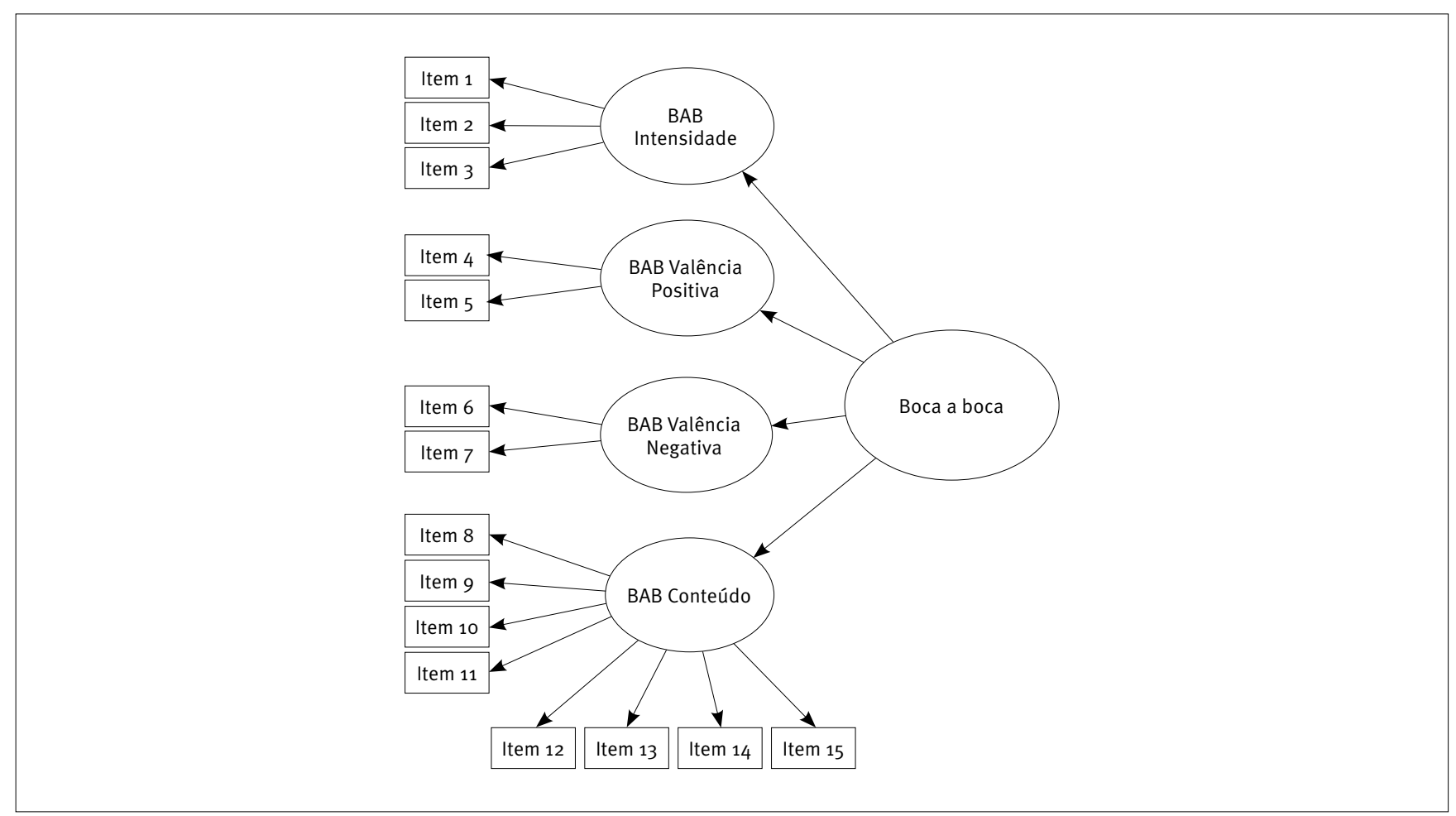

Fonte: Adaptado de Goyette et al. (2010). 
O modelo apresentado na Figura 2 é aplicado nos grupos de melhores e piores sites, de maneira separada e simultânea, a fim de tecer as análises comparativas posteriores.

No Quadro 1, é apresentado modelo de medida com a legenda de variáveis escalares. As variáveis e dimensões que representam o contexto melhores sites iniciam com a letra “M", e piores sites iniciam com a letra "P".

\section{Quadro 1. Lista de variáveis escalares}

\begin{tabular}{|c|c|c|c|}
\hline Dimensão & Item de medida & Variável Melhores sites & Variável Piores sites \\
\hline \multirow{3}{*}{$\begin{array}{l}\text { Intensidade } \\
\text { (MINT e PINT) }\end{array}$} & $\begin{array}{l}\text { Eu falo deste site com muito mais frequência do que sobre } \\
\text { qualquer outro site de varejo eletrônico }\end{array}$ & MINT1 & PINT1 \\
\hline & $\begin{array}{l}\text { Falei deste site com muito mais frequência do que sobre sites de } \\
\text { qualquer tipo }\end{array}$ & MINT2 & PINT2 \\
\hline & Eu falo deste site para muitos indivíduos & $\mathrm{MINT}_{3}$ & $\mathrm{PINT}_{3}$ \\
\hline \multirow{2}{*}{$\begin{array}{l}\text { Valência positiva } \\
\text { (MVAP e PVAP) }\end{array}$} & Eu já recomendei este site & MVAP1 & $\mathrm{PVAP}_{1}$ \\
\hline & Tenho falado favoravelmente deste site para outras pessoas & MVAP2 & $\mathrm{PVAP}_{2}$ \\
\hline \multirow{2}{*}{$\begin{array}{l}\text { Valência } \\
\text { negativa (MVAN } \\
\text { e PVAN) }\end{array}$} & Eu, principalmente, digo coisas negativas para os outros & MVAN1 & PVAN 1 \\
\hline & Eu tenho falado aspectos desfavoráveis deste site para os outros & MVAN2 & PVAN2 \\
\hline \multirow{8}{*}{$\begin{array}{l}\text { Conteúdo } \\
\text { (MCONT e } \\
\text { PCONT) }\end{array}$} & Eu discuto sobre a facilidade de uso do site & MFac & PFac \\
\hline & Eu discuto sobre a segurança das transações do site & MSeg & PSeg \\
\hline & Eu discuto sobre os preços dos produtos oferecidos & MPre & PPre \\
\hline & Eu discuto sobre a variedade dos produtos oferecidos & MVar & PVar \\
\hline & Eu discuto sobre a qualidade dos produtos oferecidos & MQua & PQua \\
\hline & Eu falo sobre a velocidade da entrega & MEnt & PEnt \\
\hline & Eu falo sobre serviços de atendimento pós-compra & MPos & PPos \\
\hline & Eu discuto sobre a confiança do site & MCon & PCon \\
\hline
\end{tabular}

Os procedimentos de coleta de dados são descritos a seguir.

\section{Coleta de dados}

0 respondente foi informado de que o escopo da pesquisa se refere a sites de varejo de bens de consumo, nos quais não serão incluídos sites de serviços eletrônicos, como internet banking e sites de compras de passagens aéreas. Ele deveria informar qual o melhor e o pior site e atribuir as respostas às questões do modelo, baseado em sua experiência prévia de consumo, em cada site indicado.

Nesta pesquisa, define-se como amostra estudantes universitários (graduação e pós-graduação), residentes na cidade de Fortaleza - CE, que tenham comprado algum produto em sites de varejo eletrônico nos dois anos anteriores à pesquisa, a fim de investigar o fenômeno com usuários experientes. Um item referente à frequência de compra mensal também foi utilizado, para identificar respondentes com hábito de compra frequente.
A coleta da pesquisa aconteceu de 22.12.2013 a 14.03.2014, resultando em 617 questionários, sendo 247 válidos. Essa eliminação foi decorrente de alguns fatores como: não indicação do site, perfil fora dos critérios da amostra, usuários com hábito de compras pouco frequente e respostas sobre sites fora do escopo de pesquisa.

Os valores omissos foram tratados por meio do método da tendência linear do ponto (Corrar, Paulo, \& Dias, 2007).

\section{Tratamento dos dados}

Foram utilizados os softwares Excel, SPSS e AMOS para tratamento da base de dados, seguindo as etapas de Hair, Anderson, Tatham, e Black (1998) e Marôco (2010), conforme descrito a seguir.

Para teste de normalidade, as variáveis escalares apresentaram índices satisfatórios (skewness menor que 2 e kurtosis menor que 7) e não foi identificada multicolinearidade (variance inflation fator [VIF] menor que 5). 
Para testar a confiabilidade das escalas em medir as dimensões, o Alfa de Cronbach deve ser acima de 0,7 (Nunnaly, 1978). Seguem, na Tabela 1, os valores indicando índices satisfatórios. Além do Alfa de Cronbach, outro indicador de confiabilidade são as correlações entre as variáveis dentro das dimensões. Todos os itens dentro das dimensões possuem correlações satisfatórias (entre 0,2 e 07), conforme recomendações de Hair et al. (1998).

\section{Tabela 1. Índices de conformidade das dimensões dos modelos}

\begin{tabular}{l|c|c|c}
\hline Contexto & Dimensão & Alfa de Cronbach & Número de itens \\
\hline \multirow{4}{*}{ Melhores sites } & Intensidade & 0,817 & 2 \\
\cline { 2 - 4 } & Valência positiva & 0,777 & 2 \\
\cline { 2 - 4 } & Valência negativa & 0,817 & 8 \\
\cline { 2 - 4 } & Conteúdo & 0,918 & 3 \\
\cline { 2 - 4 } & Intensidade & 0,885 & 2 \\
\cline { 2 - 4 } & Valência positiva & 0,707 & 2 \\
\cline { 2 - 4 } & Valência negativa & 0,905 & 8 \\
\end{tabular}

Após uma AFC de $1^{\text {a }}$ ordem, a fim de melhorar a estimação do modelo, foram desenhadas covariâncias dos erros residuais identificados por meio do índices de modificação do AMOS (Byrne, 2010). Seguem, na Tabela 2, os índices de confiabilidade composta (CC), variância média extraída (VME) e quadrado da correlação dos fatores (QCF), conforme Marôco (2010) e Hair et al. (1998), do modelo após AFC.

Tabela 2. Indicadores para confiabilidade, validade convergente e discriminante

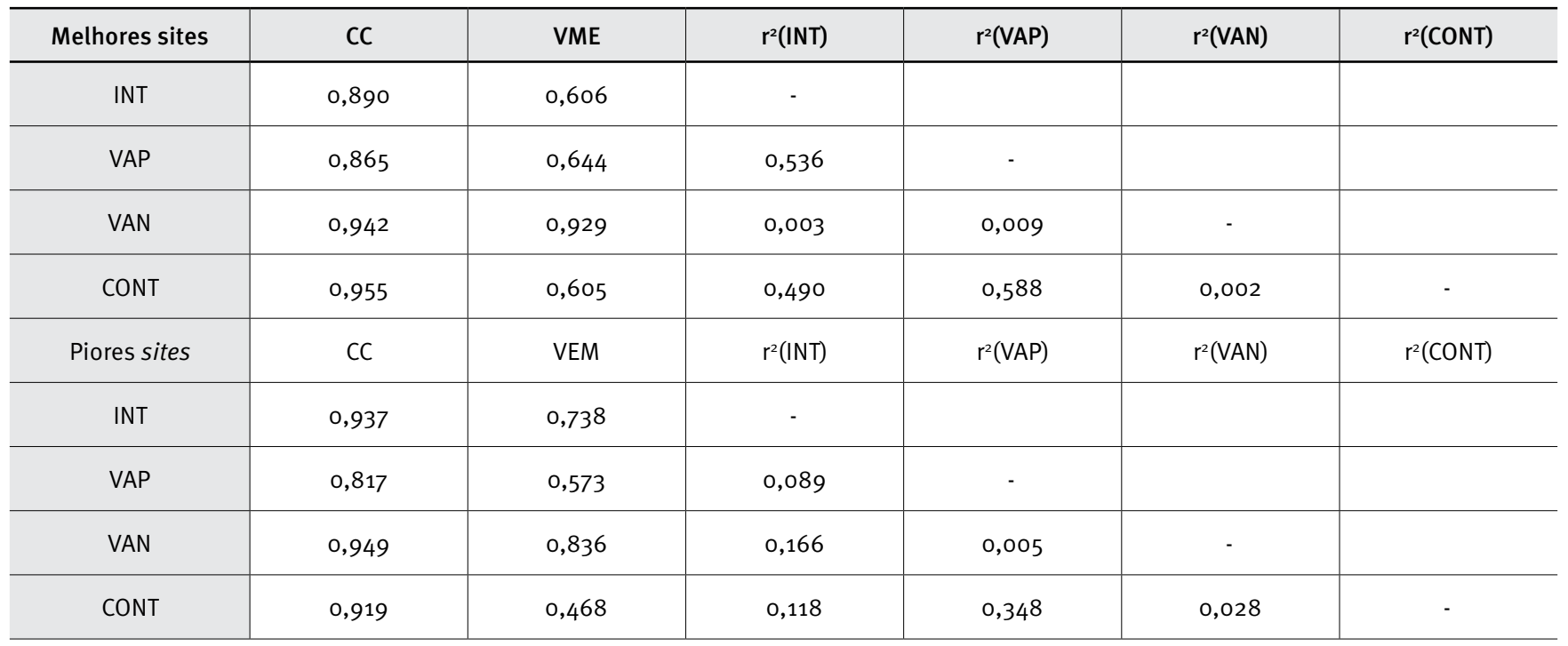

Hair et al. (1998) sugerem que, para uma confiabilidade satisfatória, CC deve ser acima de o,7. A Tabela 2 demostra que todos os construtos atingiram tal nível. Ainda segundo os autores, para uma validade convergente satisfatória, VEM deve ser acima de 0,5 e CC > VME. Para Marôco (2010, p. 188), a validade discriminante é satisfatória quando VME > QCF. Pela Tabela 2, é possível verificar que todos os fatores possuem validade discriminante satisfatória.
O modelo apresentou índices satisfatórios referentes à confiabilidade composta, validade convergente, validade discriminante e de ajustamento, considerando todos os 15 itens de pesquisa para os piores e melhores sites. Na Tabela 3, segue uma comparação dos índices de ajustamento do modelo antes e após a reespecificação: 
Tabela 3. Comparação dos índices de ajustamento entre os modelos

\begin{tabular}{|c|c|c|c|c|c|}
\hline Indicador & $\begin{array}{c}\text { Modelo original } \\
\text { melhores sites }\end{array}$ & $\begin{array}{l}\text { Modelo final } \\
\text { melhores sites }\end{array}$ & $\begin{array}{l}\text { Modelo original } \\
\text { piores sites }\end{array}$ & $\begin{array}{c}\text { Modelo final piores } \\
\text { sites }\end{array}$ & Requerido \\
\hline$x^{2}$ & 231,817 & 187,89 & 364,022 & 164,019 & - \\
\hline $\mathrm{Gl}$ & 86 & 83 & 86 & 79 & - \\
\hline P-Value & 0,000 & 0,000 & 0,000 & 0,000 & $>0,05$ \\
\hline $\mathrm{GFI}$ & 0,887 & 0,908 & 0,832 & 0,918 & $>0,90$ \\
\hline $\mathrm{NFI}$ & 0,9 & 0,919 & 0,829 & 0,923 & $>0,90$ \\
\hline TLI & 0,919 & 0,94 & 0,832 & 0,944 & $>0,90$ \\
\hline PGFI & 0,638 & 0,628 & 0,596 & 0,604 & $>0,60$ \\
\hline PCFI & 0,765 & 0,753 & 0,707 & 0,721 & $>0,60$ \\
\hline RMSEA & 0,083 & 0,072 & 0,115 & 0,066 & $<0,08$ \\
\hline
\end{tabular}

Por fim, foi realizado o teste do fator único de Harman (1960), a fim de identificar se o modelo possui problema de viés comum ao método, atribuído à variância indesejada causada pelo modelo de medição (Bagozzi \& Yi, 1991). O teste indicou valores abaixo de $50 \%$ de variância, para o grupo de variáveis de melhores e piores sites (respectivamente $47,7 \%$ e $36,5 \%$ ), indicando ausência do problema (Harman, 1960).

A seguir, é apresentada a análise dos resultados.

\section{ANÁLISE DOS RESULTADOS}

A seção análise dos resultados é composta de uma análise das estatísticas descritivas, acerca da amostra de sites apontados e verificação das hipóteses.

\section{Estatísticas descritivas}

Em relação aos melhores, 37 sites foram citados. Americanas. com apresentou 95 ocorrências, seguido de Submarino.com. Juntos, os 10 primeiros sites representam $85 \%$ da amostra. Os outros $15 \%$ foram distribuídos em 27 sites, com, no máximo, duas ocorrências cada, acumulando 37 ocorrências.

A distribuição de frequência dos melhores sites é apresentada no Gráfico 1.

\section{Gráfico 1. Distribuição de frequência dos melhores sites}

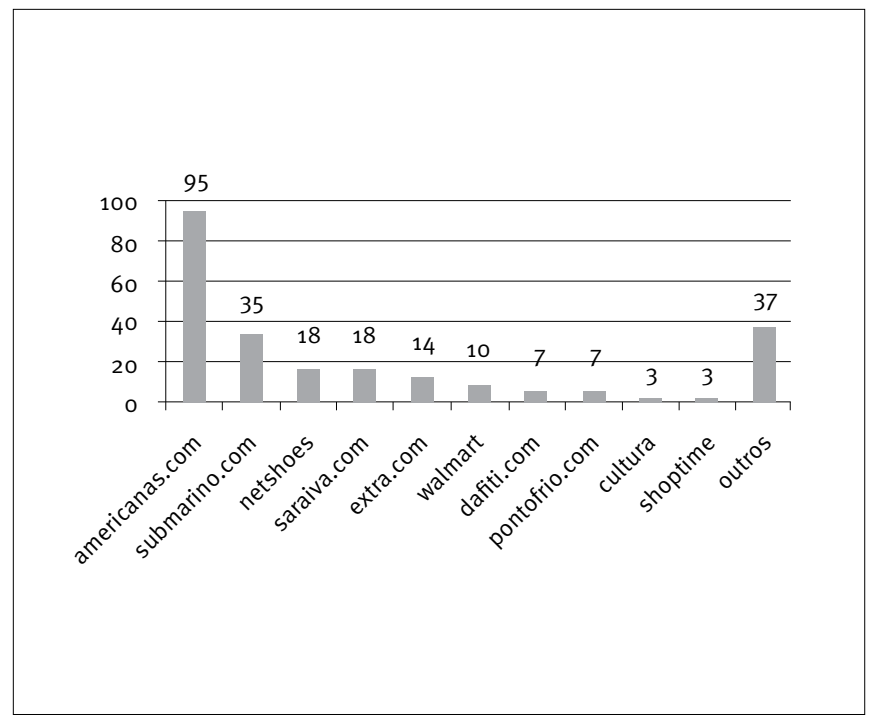

Em relação aos piores, 59 sites foram citados, com uma dispersão bem maior que os melhores sites, muitos com baixa frequência. Observa-se que Americanas.com também foi o site mais citado, seguido por Submarino.com. Os 10 primeiros sites representam $75 \%$ da amostra. Os outros $25 \%$ foram distribuídos em 49 sites com 57 ocorrências. É apresentada, no Gráfico 2, a distribuição de frequência dos piores sites. 
Gráfico 2. Distribuição de frequência dos piores sites

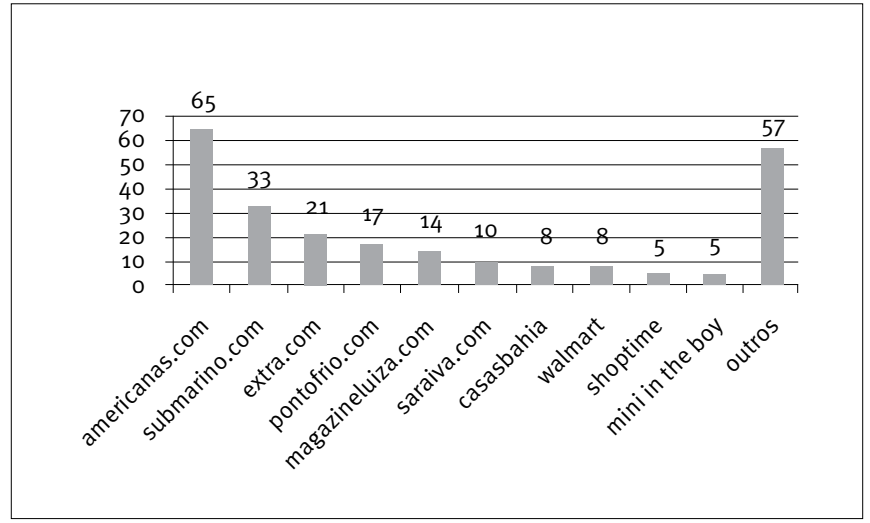

Figura 3. Modelos finais com coeficientes padronizados
Esses dados demonstram que parte das experiências negativas dos consumidores provém de sites desconhecidos, porém os sites mais populares (Comscore, 2014) estão presentes nos grupos de melhores e de piores sites. Comparando os dois grupos, sete sites revezam-se entre as 10 primeiras posições.

\section{Verificação das hipóteses}

Após os procedimentos de validação dos modelos, foram gerados os coeficientes padronizados para análise do primeiro grupo de hipóteses. Na Figura 3, é apresentado o modelo final com as cargas geradas e alguns indicadores de conformidade já apontados na Tabela 3:

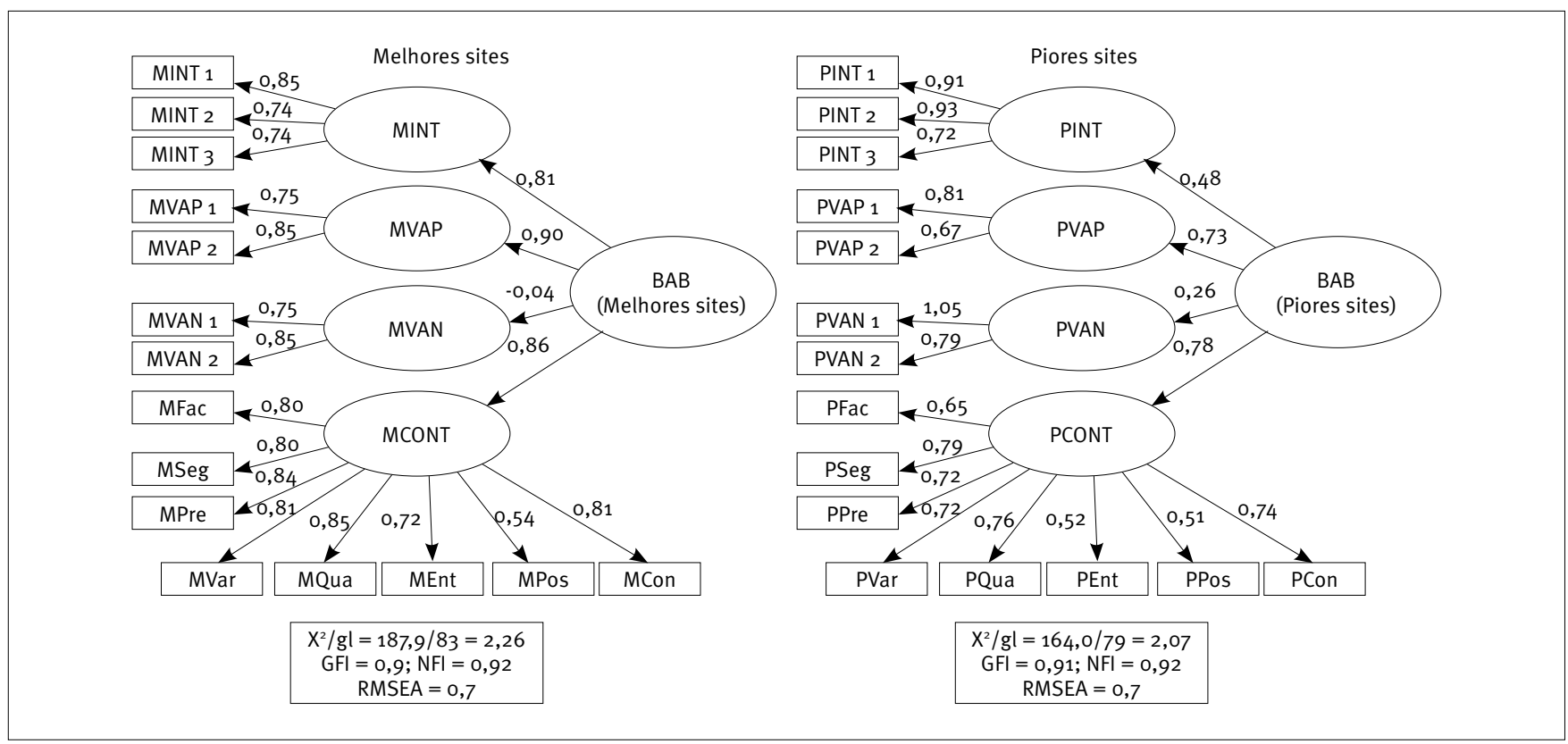

Observa-se que, nos melhores sites, as dimensões intensidade, valência positiva e conteúdo possuem alto poder explicativo do construto latente BAB, sendo os coeficientes padronizados respectivamente 0,$81 ; 0,90$ e 0,86 ( $p<0,001)$. Valência negativa não foi significativamente diferente de zero em $95 \%$. Esse resultado corrobora os achados de Goyette et al. (2010), que não apontam a presença de valência negativa em sites populares (melhores sites)

Já em relação aos piores sites, observa-se que todas as dimensões (intensidade, valência positiva, valência negativa e conteúdo) demonstraram alto poder explicativo do construto latente $B A B$, sendo os coeficientes padronizados respectivamente: $0,48 ; 0,73 ; 0,26$ e 0,78 ( $p<0,001)$.
Observa-se, ainda, que, nos piores sites, há presença tanto de valência positiva $(0,73)$ quanto de valência negativa $(0,26)$. Esses achados corroboram as pesquisas de Sandes e Urdan (2010) e Andrade e Brandão (2012) acerca da presença de valência negativa. Contudo, a presença de valência positiva nos piores sites não foi esperada. Dessa forma, em relação à dimensionalidade do $B A B$, os dados dão suporte às hipóteses de $\mathrm{H}_{1} \mathrm{a}$ a $\mathrm{H}_{4}$ b, exceto $\mathrm{H}_{1} b$.

Para verificação das hipóteses de pesquisa $\mathrm{H}_{5}$ e $\mathrm{H} 6$, utilizaram-se as matrizes de coeficientes (não padronizados) dos modelos finais, melhores e piores sites, gerados pelo AMOS para estimar os escores das dimensões por meio de regressão linear, conforme procedimento descrito por Marôco (2010, p. 
200). Para cada observação, foi calculado o escore de cada dimensão, multiplicando-se os valores dos itens das escalas Likert e coeficientes não padronizados, obtendo-se a média ponderada de cada construto para cada observação. Na Tabela 4, seguem as matrizes de coeficientes geradas pelo AMOS.

Tabela 4. Matriz de coeficientes não padronizados

\begin{tabular}{|c|c|c|c|c|c|c|c|}
\hline & MVAP1 & MVAP2 & MVAN1 & MVAN2 & MINT1 & MINT2 & MINT3 \\
\hline MVAN & 0,005 & 0,009 & 1,083 & $-0,552$ & 0,006 & 0,003 & 0,003 \\
\hline MINT & 0,032 & 0,056 & $-0,005$ & 0,002 & 0,34 & 0,186 & 0,164 \\
\hline PCONT & 0,053 & 0,025 & 0,017 & $-0,003$ & 0,013 & 0,018 & 0,004 \\
\hline PVAP & 0,417 & 0,197 & 0,018 & $-0,003$ & 0,014 & 0,019 & 0,004 \\
\hline PVAN & $-0,009$ & $-0,004$ & 0,984 & $-0,191$ & $-0,002$ & $-0,003$ & $-0,001$ \\
\hline
\end{tabular}

Com os escores calculados, foi realizado um teste de T de diferenças de médias, apresentado na Tabela 5.

Tabela 5. Teste de T de diferenças de médias

\begin{tabular}{|c|c|c|c|c|c|c|c|c|}
\hline & & \multicolumn{4}{|c|}{ Diferença emparelhada } & \multirow{3}{*}{ Teste T } & \multirow{3}{*}{ gf } & \multirow{3}{*}{$\begin{array}{c}\text { Sig. } \\
\text { (2 caudas) }\end{array}$} \\
\hline & & \multirow[t]{2}{*}{ Média } & \multirow[t]{2}{*}{ Desvio padrão } & \multicolumn{2}{|c|}{$\begin{array}{l}\text { Intervalo da diferença } \\
\text { com } 95 \% \text { de confiança }\end{array}$} & & & \\
\hline & & & & Inferior & Superior & & & \\
\hline Par 1 & $\begin{array}{l}\text { MINT_DIM - } \\
\text { PINT_DIM }\end{array}$ & 0,858 & 1,656 & 0,650 & 1,066 & 8,143 & 246 & 0,000 \\
\hline Par 2 & $\begin{array}{l}\text { PVAN_DIM - } \\
\text { MVAP_DIM }\end{array}$ & 0,267 & 1,887 & 0,030 & 0,503 & 2,222 & 246 & 0,027 \\
\hline
\end{tabular}

Analisando a Tabela 5, no Par 1, observa-se que o resultado final do escore de intensidade para os melhores sites é estatisticamente maior que o intensidade dos piores sites. Contudo, quando comparada a valência positiva dos melhores sites com valência negativa dos piores sites (Par 2), há uma inversão: o contexto negativo é superior.

Isso demonstra que, para os melhores sites, o BAB possui maior intensidade, porém, nos piores sites, a comunicação possui um maior grau de detração comparado ao grau de promoção dos melhores sites. Os resultados referentes à intensidade $\left(\mathrm{H}_{5}\right)$ não confirmam alguns achados na literatura, sobre o BAB negativo ser geralmente mais intenso (Allsop et al., 2007; Harrison-Walker, 2001; Stokes \& Lomax, 2002). Em relação à comparação de valências $(\mathrm{H} 6)$, os resultados confirmam achados na literatura (Matos, 2011; Richins, 1983; Sweeney et al., 2005) sobre o BAB negativo ser mais passional e extremo.

Para verificação das hipóteses relacionadas ao conteúdo (H7a a H11b), utilizou-se a correlação dos itens do conteúdo dos melhores sites com valência positiva dos melhores sites e itens do conteúdo dos piores sites com valência negativa dos piores sites, a partir dos mesmos escores não padronizados apresentados na Tabela 4. As correlações são apresentadas na Tabela 7. 
Tabela 6. Correlação das valências positivas e negativas com itens do conteúdo

\begin{tabular}{c|c|c|c|c|c|c|c|c}
\hline & MFac & MSeg & MPre & MVar & MQua & MEnt & MPos & MCon \\
\hline MVAP_DIM & $0,511^{* *}$ & $0,573^{* *}$ & $0,567^{* *}$ & $0,499^{* *}$ & $0,590^{* *}$ & $0,537^{* *}$ & $0,360^{* *}$ & $0,622^{* *}$ \\
\hline MVAN_DIM & $-0,110$ & $-0,079$ & $-0,088$ & $-0,050$ & $-0,050$ & 0,004 & 0,088 & $-0,072$ \\
\hline & PFac & PSeg & PPre & PVar & PQua & PEnt & PPoS PCon \\
\hline PVAP_DIM & $0,461^{* *}$ & $0,396^{* *}$ & $0,388^{* *}$ & $0,419^{* *}$ & $0,422^{* *}$ & $0,187^{* *}$ & $0,153^{*}$ & $0,308^{* *}$ \\
\hline PVAN_DIM & 0,099 & 0,098 & $0,209^{* *}$ & $0,131^{*}$ & 0,043 & $0,150^{*}$ & $0,206^{* *}$ & $0,143^{*}$ \\
\hline
\end{tabular}

Nota: **. A correlação é significante no nível o,01 (2 extremidades); *. A correlação é significativa no nível o,05 (2 extremidades).

Em relação aos melhores sites, todos os itens apresentam correlação com valência positiva. Dessa forma, as hipóteses $\mathrm{H} 7 \mathrm{a}$, H7a e H9a são suportadas, e as hipóteses H10a e H11a não são suportadas.

Em relação aos piores sites, apenas facilidade de uso e segurança nas transações não apresentaram correlações significativas com valência negativa. Dessa forma, as hipóteses H7b, H8b, Hgb, H1ob e H11b são suportadas.

Esses resultados confirmam achados na literatura que predizem que, quanto maior confiança, maior a predisposição do consumidor para comprar no comércio eletrônico ou continuar comprando em determinado site (Baptista \& Botelho, 2007; Schramm-Klein et al., 2007; Turban \& King, 2004), e que isso consequentemente gera valor de conversa em comunicação BAB.

Esse é um comportamento semelhante a quando se trata de atendimento pós-compra e velocidade de entrega (Baptista \& Botelho, 2007; Barreto et al., 2011; Forbes et al., 2005; Lima, 2010; Turban \& King, 2004).

Em relação à facilidade de uso e segurança nas transações, os resultados corroboram a literatura sobre sua relevância (Turban \& King, 2004; Vieira et al., 2009). Contudo, não era esperado que esses fatores reforçassem a comunicação $B A B$ positiva dos melhores sites, assim, as hipóteses $\mathrm{H}_{10} \mathrm{Oa}$ e H11a não foram suportadas. No entanto, não houve evidências de que esses fatores reforçassem a comunicação $B A B$ negativa dos piores sites, dando suporte às hipóteses H1ob e H11b.

Esses resultados corroboram, pelo menos em parte, os achados de Lima (2010) e Costa e Marques (2011) sobre a comoditização desses atributos entre melhores e piores sites. Todavia, é necessário realizar mais estudos para confirmar tal comportamento.

0 resumo das hipóteses é apresentado na Tabela 7
Tabela 7. Resumo dos resultados das hipóteses

\begin{tabular}{|c|c|c|c|}
\hline Hipótese & Construtos & Condição & $\begin{array}{l}\text { Suporte dos } \\
\text { resultados }\end{array}$ \\
\hline $\mathrm{H}_{1} \mathrm{a}$ & MINT e MBAB & relação & Sim \\
\hline $\mathrm{H}_{1} \mathrm{~b}$ & PINT e PBAB & relação & Sim \\
\hline $\mathrm{H} 2 \mathrm{a}$ & MVAP e MBAB & relação & Sim \\
\hline $\mathrm{H} 2 \mathrm{~b}$ & PVAP e PBAB & sem relação & Não \\
\hline Нза & MVAN e MBAB & sem relação & Sim \\
\hline $\mathrm{H}_{3} \mathrm{~b}$ & PVAN e PBAB & relação & Sim \\
\hline $\mathrm{H}_{4} \mathrm{a}$ & MCONT e MBAB & relação & Sim \\
\hline $\mathrm{H}_{4} \mathrm{~b}$ & PCONT e PBAB & relação & Sim \\
\hline $\mathrm{H}_{5}$ & PINT e MINT & $1^{\circ}$ maior que $2^{\circ}$ & Não \\
\hline $\mathrm{H} 6$ & PVAN e MVAP & $1^{\circ}$ maior que $2^{\circ}$ & Sim \\
\hline $\mathrm{H} 7 \mathrm{a}$ & MVAP e MCon & relação & Sim \\
\hline $\mathrm{H} 7 \mathrm{~b}$ & PVAN e PCon & relação & Sim \\
\hline $\mathrm{H} 8 \mathrm{a}$ & MVAP e MPos & relação & Sim \\
\hline $\mathrm{H} 8 \mathrm{~b}$ & PVAN e PPos & relação & Sim \\
\hline $\mathrm{Hga}$ & MVAP e MEnt & relação & Sim \\
\hline $\mathrm{Hgb}$ & PVAN e PEnt & relação & Sim \\
\hline H1oa & MVAP e MFac & sem relação & Não \\
\hline $\mathrm{H} 1 \mathrm{ob}$ & PVAN e PFac & sem relação & Sim \\
\hline $\mathrm{H} 11 \mathrm{a}$ & MVAP e MSeg & sem relação & Não \\
\hline $\mathrm{H}_{11 \mathrm{~b}}$ & PVAN e PSeg & sem relação & Sim \\
\hline
\end{tabular}

A seguir, é apresentada a conclusão da pesquisa. 


\section{CONCLUSÃO}

O objetivo desta pesquisa foi analisar os fatores internos do BAB no varejo eletrônico no Brasil, comparando os melhores e piores sites apontados por consumidores, com as seguintes questões de partida: (1) como se estabelecem as dimensões intensidade e valências entre melhores e piores sites; e (2) como os fatores da dimensão conteúdo se relacionam com as demais valências do BAB nos piores e nos melhores sites.

O modelo de mensuração base foi de Goyette et al. (2010), que mede o $B A B$ no varejo eletrônico em quatro dimensões: intensidade, valência positiva, valência negativa e conteúdo. Em função de considerações levantadas na literatura sobre varejo eletrônico geral e brasileiro, foram incluídos novos itens ao modelo original, a fim de captar mais detalhes sobre a dimensão conteúdo do BAB.

O modelo modificado nesta pesquisa apresentou índices satisfatórios de ajustamento, confiabilidade e validade. Como resultado, foi possível observar alguns achados descritos a seguir.

Em relação à multidimensionalidade do $B A B$, os resultados apontaram a existência de valência negativa nos piores sites, corroborando Sandes e Urdan (2010), Andrade e Brandão (2012), e indo de encontro a Goyette et al. (2010), que não apontou a presença significativa de valência negativa para sites do Canadá. Assim, esse resultado não fornece suporte à generalização de Goyette et al. (2010) sobre a predominância de valência positiva no comércio eletrônico de maneira geral.

Em relação à questão: como se estabelecem as dimensões intensidade e valências em relação aos melhores e piores sites, a pesquisa forneceu evidências de que a intensidade é maior nos melhores sites. Isso alimenta uma divergência na literatura, pois não dá suporte a achados que apontam que as pessoas tendem a se engajar mais em mensagens negativas do que em positivas (Allsop et al., 2007; Harrison-Walker, 2001; Stokes \& Lomax, 2002).

Para este caso, é importante ressaltar que os principais players do mercado foram citados (Comscore, 2014), e que os líderes de mercado se revezam entre as primeiras posições como os mais frequentes no grupo dos melhores e de piores sites, apontados por respondentes distintos. Como a amostra mais significativa da pesquisa refere-se a um conjunto de sites que está presente em ambos os grupos, e esse conjunto é formado por sites populares e mais acessados, seria plausível que o $B A B$ dos melhores sites fosse mais intenso, dada uma relação da recomendação de uso com a liderança de mercado.

Dessa forma, apesar de a literatura encontrar evidências de uma maior intensidade no BAB negativo, os resultados desta pesquisa apontam que, para sites preferidos pelos consumidores, há uma maior intensidade acerca de BAB positivo.
No entanto, a pesquisa apresentou evidências de que a valência negativa dos piores sites é maior que a valência positiva dos piores sites, ou seja, a comunicação BAB dos piores sites tem um maior grau de detração em relação ao grau de promoção da comunicação BAB dos melhores sites. Esse resultado confirma achados na literatura sobre um comportamento mais passional e extremo na comunicação BAB negativa (Matos, 2011; Richins, 1983; Sweeney et al., 2005).

Já em relação à questão: como os fatores da dimensão conteúdo se relacionam com as demais valências do BAB, há as seguintes considerações sobre os itens analisados.

Em relação à confiança, a pesquisa apontou evidências de haver correlação significativa do item com valência positiva nos melhores sites e com valência negativa nos piores sites. Esses resultados confirmam achados na literatura que predizem que, quanto maior confiança, maior a predisposição do consumidor para comprar no comércio eletrônico ou continuar comprando em determinado site (Baptista \& Botelho, 2007; Schramm-Klein et al., 2007; Turban \& King, 2004). Esse fator gera implicações relevantes para o fenômeno $B A B$, dado que esta pesquisa aponta que os consumidores conversam sobre confiança de sites com outros consumidores e que esse tópico está fortemente associado às valências (positiva e negativa), gerando possivelmente implicações em outros fenômenos como intenção de compra.

Os resultados da pesquisa também apontaram comportamento semelhante quando se trata de atendimento pós-compra e velocidade de entrega como fatores relevantes, como apresenta a literatura (Baptista \& Botelho, 2007; Barreto et al., 2011; Forbes et al., 2005; Lima, 2010; Turban \& King, 2004).

Em relação à facilidade de uso e segurança nas transações, os resultados apontam que esses fatores ainda estão fortemente relacionados à valência positiva nos melhores sites, mas já não tiveram relação significativa com valência negativa nos piores sites.

Esses resultados reforçam o fato de que tais fatores são relevantes para os consumidores no varejo eletrônico (Turban \& King, 2004; Vieira et al., 2009) e que isso implica comunicação BAB positiva para melhores sites. Da mesma forma, demonstram, pelo menos em parte, que há um certo grau de comoditização desses atributos (Costa \& Marques, 2011; Lima, 2010), pois já não são fatores críticos para os piores sites, com implicações em BAB negativo. No entanto, esses achados precisam ser investigados com mais profundidade.

Esta pesquisa fornece alguns insumos para trabalhos futuros. Do ponto de vista metodológico, contribui com a formulação de um modelo de mensuração multidimensional do BAB, adaptado de Goyette et al. (2010) para o varejo eletrônico brasileiro, capaz de captar aspectos relevantes do construto e 
aplicado a contextos diferentes (melhores e piores sites). Do ponto de vista teórico, este trabalho contribui com achados que reforçam a literatura do campo em relação a aspectos intrínsecos ao fenômeno BAB, como as relações entre suas dimensões internas, evidenciando fatores importantes do varejo eletrônico presentes na comunicação BAB.

Este estudo possui algumas limitações. Primeiro, a amostra foi restrita à cidade de Fortaleza - CE, apenas com estudantes de graduação e pós-graduação, pelo método de amostragem por conveniência. Segundo, em relação ao instrumento de pesquisa, a grande quantidade de itens pode ter afetado o engajamento do respondente em relação à segunda parte do instrumento de pesquisa (referente aos piores sites), o que ocasionou também, a eliminação de diversos questionários. Dessa forma, diversas observações tiveram que ser eliminadas. Outro fator limitante em relação ao questionário é que ele busca respostas baseadas em experiências passadas, as quais dependem da memória do respondente para aferir uma resposta sobre o fenômeno pesquisado.

Para pesquisas futuras, sugere-se verificar como a dimensão conteúdo poderia ser dividida em outras duas dimensões, uma especificamente para aspectos relacionados aos produtos comercializados (preço, qualidade e variedade) e outra agrupando aspectos relacionados ao canal em si (confiança, velocidade de entrega, atendimento pós-compra, facilidade de uso e segurança nas transações), a fim de entender o fenômeno $\mathrm{BAB}$ distinguindo aspectos específicos do canal e aspectos dos produtos ofertados. A fim de validar os achados desta pesquisa em outros contextos, sugere-se também a replicação deste estudo em outras regiões do País.

\section{REFERÊNCIAS}

Allsop, D. T., Bryce, R. B., \& Hoskins, J. A. (2007). Word-of-mouth research: Principles and applications. Journal of Advertising Research, 47(4), 388-411. doi:10.2501/s0021849907070419

Andrade, D. M., \& Brandão, M. M. (2012). Boca a boca eletrônico como forma de retaliação: Uma aplicação da modelagem de equações estruturais para determinar o comportamento pós-reclamação de consumidores insatisfeitos/ofendidos. Revista ADM. MADE, 16(1), 24-44.

Bagozzi, R. P., \& Yi, Y. (1991). Multitrait-multimethod matrices in consumer research. Journal of Consumer Research, 17(4), 426-439.

Baptista, C. S., \& Botelho, D. (2007). Escolha de canais de venda em comércio eletrônico. Revista de Administração Mackenzie, 8(1), 59-76.

Barreto, M., Hor-Meyll, L. F., Chauvel, M. A., \& Araújo, F. F. de. (2011). Por que os consumidores ficam insatisfeitos com compras on-line? 60 Congresso do Instituto Franco-Brasileiro de Administração de Empresas (IFBAE), Franca, SP.
Bickart, B., \& Schindler, R. M. (2001). Internet forums as influential sources of consumer information. Journal of Interactive Marketing, 15(3), 31-40. doi:10.1002/dir.1014

Byrne, B. M. (2010). Structural equation modeling with AMOS: Basic concepts, applications, and programming (2nd ed.). New York, EUA: Routledge.

Bone, P. F. (1992). Determinants of word-of-mouth communication during product consumption. Advances in Consumer Research, 19(1), 579-583.

Chang, M. K., Cheung, W., \& Lai, V. S. (2005). Literature derived reference models for the adoption of online shopping. Information \& Management, 42(4), 543-559. doi:10.1016/j.im.2004.02.006

Cheung, C. M. K., \& Thadani, D. R. (2010). The effectiveness of electronic word-of-mouth communication: A literature analysis. Proceedings of the 23 rd Bled eConference eTrust: Implications for the Individual, Enterprises and Society, Bled, Eslovênia.

Chevalier, J. A., \& Mayzlin, D. (2006). The effect of word of mouth on sales: Online book reviews. Journal of Marketing Research, 43(3), 345-354. doi:10.1509/jmkr.43.3.345

Comscore. (2014). Brazil digital future in focus 2014. Recuperado de https://www.comscore.com/por/Imprensa-e-eventos/Press-Releases/2014/5/Estudo-da-comScore-Brazil-Digital-Future-in-Focus-2014-esta-disponivel

Corrar, L. J., Paulo, E., \& Dias, J. M., Filho. (2007). Análise multivariada. São Paulo, SP: Atlas.

Costa, E. M., \& Marques, E. V. (2011). Usabilidade: Um estudo da percepção de qualidade no comércio eletrônico brasileiro. Anais do 350 Encontro Anual da Associação Nacional dos Programas de PósGraduação em Administração, Rio de Janeiro, RJ.

Dhar, V., \& Chang, E. (2009). Does chatter matter? The impact of usergenerated content on music sales. Journal of Interactive Marketing, 23(4), 300-307. doi:10.1016/j.intmar.2009.07.004

Forbes, L. P., Kelley, S. W., \& Hoffman, K. D. (2005). Typologies of e-commerce retail failures and recovery strategies. Journal of Services Marketing, 19(5), 280-292. doi:10.1108/08876040510609907

Gauri, D., Bhatnagar, A., \& Rao, R. (2008). Role of word of mouth in online store loyalty. Communications of the ACM, 51(3), 89-91. doi:10.1145/1325555.1325572

Goyette, I., Ricard, L., Bergeron, J., \& Marticotte, F. (2010, March). e-WOM scale: Word-of-mouth measurement scale for e-services context. Canadian Journal of Administrative Sciences, 27(1), 5-23. doi:10.1002/cjas.129

Grazioli, S., \& Javenpaa, S. (2000). Perils of internet fraud: An empirical investigation of deception and trust with experienced internet consumers. Transactions on Systems, Man and Cybernetics, Part A: Systems and Humans, 30(4), 395-410. doi:10.1109/3468.852434

Hair, J. F., Anderson, R. E., Tatham, R. L., \& Black, W. C. (1998). Multivariate data analysis (5th ed.). New Jersey, EUA: Prentice Hall, Upper Sanddle River.

Harman, H. H. (1960). Modern factor analysis. Chicago, EUA: University of Chicago Press.

Harrison-Walker, L. J. (2001). The measurement of word-of-mouth communications and an investigation of service quality and customer commitment as potential antecedents. Journal of Service Research, 4(1), 60-75. doi:10.1177/109467050141006 
Henning-Thurau, T., Gwinner, K. P., Walsh, G., \& Gremler, D. D. (2004). Electronic word of mouth via consumer opinion platforms: What motivates consumers to articulate themselves on the Internet? Journal of Interactive Marketing, 18(1), 38-52. doi:10.1002/dir.10073

Khare, A., Labrecque, L. I., \& Asare, A. K. (2011). The assimilative and contrastive effects of word-of-mouth volume: An experimental examination of online consumer ratings. Journal of Retailing, 87(1), 111-126. doi:10.1016/j.jretai.2011.01.005

Kozinets, R. V., Valck, K. De, Wojnicki, A. C., \& Wilner, S. J. S. W. (2010). Networked narratives: Understanding word-of-mouth marketing in online communities. Journal of Marketing, 74(2), 71-89. doi:10.1509/ jmkg.74.2.71

Kumar, N., \& Benbasat, I. (2006). Research note: The influence of recommendations and consumer reviews on evaluations of websites. Information Systems Research, 17(4), 425-439. doi:10.1287/ isre.1060.0107

Lima, L. A. (2010). (Des)Caminhos da inovação no e-tail brasileiro. Anais do 40 Encontro de Marketing da ANPAD, Rio de Janeiro, RJ.

Marôco, J. (2010). Análise de equações estruturais: Fundamentos teóricos, software \& aplicações. Lisboa, Portugal: ReportNumber.

Matos, C. A. (2011). Uma generalização empírica sobre comunicação boca a boca usando meta-análise. RAC-Revista de Administração Contemporânea, 15(5), 877-896. doi:10.1590/s141565552011000500006

McKnight, D. H., \& Chervany, N. L. (2001). What trust means in e-commerce customer relationships: An interdisciplinary conceptual typology. International Journal of Electronic Commerce, 6(2), 35-59. doi:10.1080/10864415.2001.11044235

Moshrefjavadi, M. H., Dolatabadi, H. R., Noubarkhsh, M., Poursaeedi, A., \& Asadollahi, A. (2012). An analysis of factors affecting on online shopping behavior of consumers. International Journal of Marketing Studies, 4(5), 81-98. doi:10.5539/ijms.v4n5p81

Nunnaly, J. (1978). Psychometric theory. New York, EUA: McGraw-Hill.

Parasuraman, A., Zeithaml, V. A., \& Berry, L. L. (1988). Servqual. Journal of Retailing, 64(1), 12-40.

Park, C., \& Lee, T. (2009). Information direction, website reputation and eWOM effect: A moderating role of product type. Journal of Business Research, 62(1), 61-67. doi:10.1016/j.jbusres.2007.11.017

Richins, M. L. (1983). Negative word-of-mouth by dissatisfied consumers: A pilot study. Journal of Marketing, 47(1), 68-78. doi:10.2307/3203428
Sandes, F. S., \& Urdan, A. T. (2010). Impactos sobre o consumidor e gerenciamento pela empresa do boca a boca gerado na internet: Investigações exploratória e experimental. Anais do 340 Encontro Anual da Associação Nacional dos Programas de Pós-Graduação em Administração, Rio de Janeiro, RJ.

Schramm-Klein, H., Swoboda, B., \& Morscheet, D. (2007). Internet vs. brick-and-mortar stores-analyzing the influence of shopping motives on retail channel choice among internet users. Journal of Customer Behaviour, 6(1), 19-36. doi:10.1362/147539207X198356

Srinivasan, S. S., Anderson, R., \& Ponnavolu, K. (2002). Customer loyalty in e-commerce: An exploration of its antecedents and consequences. Journal of Retailing, 78(1), 41-50. doi:10.1016/ Soo22-4359(01)00065-3

Stokes, D., \& Lomax, W. (2002). Taking control of word of mouth marketing: The case of an entrepreneurial hotelier. Journal of Small Business and Enterprise Development, 9(4), 349-357. doi:10.1108/14626000210450531

Subramani, M. R., \& Rajagopalan, B. (2003). Knowledge-sharing and influencein onlinesocialnetworksviaviralmarketing. Communications of the ACM, 46(12), 300-307. doi:10.1145/953460.953514

Sweeney, J. C., Soutar, G. N., \& Mazzarol, T. (2005, December). The difference between positive and negative word-of-mouth - emotion as a differentiator. Anais do ANZMAC Conference: Broadening the Boundaries, Perth, Australia.

Tubenchlak, D. B., Faveri, D. De., Zanini, M. T., \& Goldszmidt, R. (2015). Motivações da comunicação boca a boca eletrônica positiva entre consumidores no Facebook. RAC-Revista de Administração Contemporânea, 19(1), 107. doi:10.1590/1982-7849rac20151998

Turban, E., \& King, D. (2004). Comércio eletrônico: Estratégia e gestão. São Paulo, SP: Prentice Hall.

Vieira, V. A., Matos, C. A., \& Slongo, L. A. (2009). Avaliação das relações entre qualidade de serviço do site, satisfação, valor percebido, lealdade e boca boca por meio de um modelo teórico. Revista de Administração, 44(2), 131-146.

Webshoppers. (2013). Balanço do 20 trimestre de 2013 (28a ed.). Recuperado de http://www.ebitempresa.com.br

Westbrook, R. A. (1987). Product/Consumption-based affective responses and postpurchase processes. Journal of Marketing Research, 24(3), 258-270. doi:10.2307/3151636 